\title{
EDITORIAL
}

\section{Hospital-acquired pneumonia in Europe}

\author{
A. Torres*, S. Ewig ${ }^{\#}$, H. Lode ${ }^{\top}$ and J. Carlet ${ }^{+}$
}

T he appropriate management and prevention of hospitalacquired pneumonia (HAP) remain major medical challenges. Much work has been done in this field in the last two decades, which has been constantly summarised in several extensive reviews [1-6]. Unsurprisingly, many issues regarding diagnosis, treatment and prevention of HAP continue to be highly controversial. Some issues have recently only begun to attract the attention they deserve, e.g. the impact of distinct surgical settings and the relationship between tracheostomy and pneumonia, as well as bronchitis and pneumonia. Finally, the alarming worldwide increase in microbial resistance forces us to redefine strategies of targeted and effective antimicrobial treatment [7].

A mainstay of progress was the release of the American Thoracic Society (ATS) guidelines in 1996 [8], which were updated as ATS/Infectious Diseases Society of America (IDSA) guidelines in 2005 [9]. These guidelines were the first to cover a wide range of issues related to HAP and ventilator-associated pneumonia (VAP), providing a clinically useful framework for the establishment of local diagnostic, therapeutic and preventive strategies [10]. Several European experts were also asked to join the committee, resulting in a balanced statement regarding American and European views. As a result, the guidelines also turned into a major reference and framework for ongoing investigation.

It is mainly for these reasons that in contrast to communityacquired pneumonia [11], European guidelines for HAP and VAP have yet to be published. A report by a European Taskforce Group [12] has supplemented the ATS/IDSA guidelines. Several European experts have consented in the view that an adjunctive European statement addressing some issues uncovered in the guidelines update would be very valuable. They feel that more emphasis should be given to non-controversial areas in order to reinforce the establishment of evidence-based standards in routine practice, but also to controversial or unknown areas in order to stimulate research in the field. Therefore, the scientific committees of the European Respiratory Society (ERS), the European Society of

\footnotetext{
*Servei de Pneumologia, Institut Clínic del Tòrax, Hospital Clinic, Universitat de Barcelona, Barcelona, Spain. ${ }^{\#}$ Thoraxzentrum Ruhrgebiet, Kliniken für Pneumologie und Infektiologie, Ev. Krankenhaus Herne und Augusta-Kranken-Anstalt, Bochum, and "Lungenklinik Heckeshorn, Berlin Germany. ${ }^{+}$Groupe Hospitalier Paris Saint Joseph, Paris, France.

STATEMENT OF INTEREST: Statements of interest for all authors can be found at www.erj.ersjournal. $\mathrm{com} / \mathrm{misc} /$ statements.dtl

CORRESPONDENCE: A. Torres, Institut Clínic del Tòrax, Servei de Pneumologia, Hospital Clínic de Barcelona, c. Villarroel, 170, 08036 Barcelona, Spain. Fax: 349322798 13. E-mail: atorres@ub.edu
}

Clinical Microbiology and Infectious Diseases (ESCMID) and the European Society of Intensive Care Medicine (ESICM) nominated three representatives who suggested members of the societies to join a panel. This panel worked on a list of topics and achieved a consensus according to predefined procedures. The document arising from this has now been published in Intensive Care Medicine [13].

The document [13] begins with a statement of 20 points of agreement between the experts. It is worth noting that this body of consensus is high, reflecting the impressive progress that has been made in the understanding and management of HAP and VAP. The experts suggest the alternative term "ventilationassociated pneumonia", thereby eliminating the terminological flaw that insinuates an association of the ventilator and pneumonia but also avoiding the need to change the wellestablished acronym "VAP". In terms of diagnostic procedures, a clear statement is made that both noninvasive and invasive approaches work, and that no advantage of the invasive approach with regard to mortality has previously been demonstrated [14], but that it is advisable to use quantitative cultures. At the same time, in the presence of suspected ventilation-associated pneumonia, the importance of immediate administration of appropriate antimicrobial treatment is stressed, and consideration of stopping antimicrobial treatment is recommended in previously untreated patients with negative cultures unless there is a high clinical likelihood of pneumonia [13]. The consensus in the document by TORRES et al. [13] is remarkably broad if we consider the extensive controversy about this subject in the past $[15,16]$. A very balanced statement is made about selective digestive contamination (SDD), stressing that SDD using parenteral antimicrobial drugs should not be lumped together with topical SDD approaches. In fact, SDD should be further evaluated in settings with increased risk for multi-resistant pathogens.

Four issues that either are not or are only partially covered in the ATS/IDSA guidelines [9] are discussed in the document by TORRES et al. [13]: HAP and VAP as quality indicators; tracheostomy and VAP; tracheobronchitis; and post-operative pneumonia. The experts express many concerns regarding the use of HAP/VAP as quality indicators [13], mainly based on the consideration that HAP is not a completely preventable condition and that the risk for HAP is very diverse across patient populations and hospital settings. Although tracheostomy is frequently performed in many intensive care units, its role regarding HAP remains uncertain. In fact, it is not clear whether tracheostomy is a risk factor or protective. Tracheobronchitis in ventilated patients has only recently been the subject of study, resulting in the finding that although tracheobronchitis is associated with adverse outcomes, its 
antimicrobial treatment does not seem to have a benefit [13]. The literature dedicated to post-operative pneumonia is scarce, and only one randomised study was published evaluating antimicrobial treatment of this condition in non-neutropenic surgical patients [13].

Microbiology is covered in the document by TORRES et al. [13] and the most recent European trends in microbial and resistance patterns are reviewed. Overall, increasing rates of methicillinresistant Staphylococcus aureus (MRSA), extended spectrum $\beta$ lactamases (ESBL), and multiresistant nonfermenters, although with remarkable regional variations, are cause for serious concern. Diagnostic approaches and recommendations for empiric initial antimicrobial treatment provide a detailed framework for physicians seeking advice in routine care for critically ill patients. These recommendations are focused on the avoidance of antimicrobial overtreatment, while ensuring immediate empirical antimicrobial coverage according to the concept of defined time frames (early versus late-onset pneumonia) and modifying risk factors. Emphasis is placed upon the potential for optimising antimicrobial treatment according to the pharmacokinetic properties of the agents selected for treatment, de-escalation, shortening of treatment, assessment of treatment response and failure of treatment. Finally, preventive strategies are weighted, resulting in generally recommended general and specific measures, as well as additional measures that might be helpful in particular settings and populations.

Overall, the document by TORRES et al. [13] reflects current opinion of leading European experts in the field and thereby adds an important contribution to the ongoing discussion concerning management of patients at risk and with suspected ventilator-associated pneumonia. Several proposals with regard to issues of definition are made, which await critical discussion. TORRES et al. [13] avoided following the American concept of healthcare-associated pneumonia, mainly due to the lack of supporting European data [9]. What is clear is that there are several standards of care no physician should fail to meet. Although complex and not always easy to establish, every effort should be made to comply with these standards. In addition, this document should be read as a call for investigation around important issues that should be addressed, the most urgent of which is the relation of tracheostomy and tracheobronchitis to hospital-acquired pneumonia, postoperative pneumonia in different settings, and new treatment approaches, such as antimicrobial inhalation treatment. The authors hope that the document by TORRES et al. [13] will receive the attention required.

\section{REFERENCES}

1 Leong JR, Huang DT. Ventilator-associated pneumonia. Surg Clin North Am 2006; 86: 1409-1429.
2 Porzecanski I, Bowton DL. Diagnosis and treatment of ventilator-associated pneumonia. Chest 2006; 130: 597-604.

3 Chastre J, Fagon JY. Ventilator-associated pneumonia. Am J Respir Crit Care Med 2002; 165: 867-903.

4 Pieracci FM, Barie PS. Strategies in the prevention and management of ventilator-associated pneumonia. Am Surg 2007; 73: 419-432.

5 Ewig S, Torres A. Flexible bronchoscopy in nosocomial pneumonia. Clin Chest Med 2001; 22: 263-279.

6 Aarts MA, Hancock JN, Heyland D, McLeod RS, Marshall JC. Empiric antibiotic therapy for suspected ventilator-associated pneumonia: a systematic review and meta-analysis of randomized trials. Crit Care Med 2008; 36: 108-117.

7 Boucher HW, Talbot GH, Bradley JS, et al. Bad bugs, no drugs: No ESKAPE! An update from the Infectious Diseases Society of America. Clin Infect Dis 2009; 48: 1-12.

8 American Thoracic Society. Hospital-acquired pneumonia in adults: diagnosis, assessment of severity, initial antimicrobial therapy, and preventive strategies. Am J Respir Crit Care Med 1996; 153: 1711-1725.

9 American Thoracic Society. Guidelines for the management of adults with hospital-acquired, ventilator-associated, and healthcare-associated pneumonia. Am J Respir Crit Care Med 2005; 171: 388-416.

10 Dellit TH, Chan JD, Skerrett SJ, Nathens AB. Development of a guideline for the management of ventilator-associated pneumonia based on local microbiologic findings and impact of the guideline on antimicrobial use practices. Infect Control Hosp Epidemiol 2008; 29: 525-533.

11 Woodhead M, Blasi F, Ewig S, et al. Guidelines for the management of adult lower respiratory tract infections. Eur Respir J 2005; 26: 1138-1158.

12 Torres A, Carlet J, and the European Task Force on Ventilator-associated Pneumonia. Ventilator-associated pneumonia. Eur Respir J 2001; 17: 1034-1045.

13 Torres A, Ewig S, Lode H, Carlet J, for the European HAP working group. Defining, treating and preventing hospital acquired pneumonia: European perspective. Intensive Care Med 2009; 35: 9-29.

14 The Canadian Critical Care Trials Group. A randomized trial of diagnostic techniques for ventilator-associated pneumonia. New Engl J Med 2006; 355: 2619-2629.

15 Niederman MS, Torres A, Summer W. Invasive diagnostic testing is not needed routinely to manage suspected ventilator-associated pneumonia. Am J Respir Crit Care Med 1994; 150: 565-569.

16 Chastre J, Fagon JY. Invasive diagnostic testing should be routinely used to manage ventilated patients with suspected pneumonia. Am J Respir Crit Care Med 1994; 150: 570-574. 